J. Dairy Sci. 92:1253-1264

doi:10.3168/jds.2007-0824

(c) American Dairy Science Association, 2009.

\title{
Characterization of distributions of somatic cell counts
}

\author{
J. ten Napel, ${ }^{\star 1}$ Y. de Haas, $\dagger^{\star}$ G. de Jong,† T. J. G. M. Lam,‡ W. Ouweltjes, ${ }^{\star}$ and J. J. Windig ${ }^{\star}$ \\ ${ }^{*}$ Animal Sciences Group, Wageningen UR, PO Box 65, 8200 AB Lelystad, the Netherlands \\ †NRS Animal Evaluation Unit, PO Box 454, 6800 AL Arnhem, the Netherlands \\ ¥GD Animal Health Service, PO Box 9, 7400 AA Deventer, the Netherlands
}

\begin{abstract}
There is more useful information in distributions of somatic cell count (SCC) than is currently used in practice. Analysis of SCC of individual quarters $(\mathrm{n}=$ 450,834 quarter records of 133,102 cows) showed that the presence of pathogens did not change the peak of the SCC distribution. Instead, the percentages of observations in the tail changed. Probability density functions of specified sets of up to 5 standard distributions were then fitted on the number of records per class, using a maximum likelihood procedure. Analysis of cow SCC ( 2 data sets: $\mathrm{n}=335,135$ test-day records of 41,567 cows on 407 farms and $n=1,665,431$ test-day records) showed that a mixture of a normal, a log-normal and an exponential density function $(\mathrm{N}+\mathrm{LN}+\mathrm{E})$ best described the distribution of SCC. A mixture of 4 normal and an exponential distribution $(4 \mathrm{~N}+\mathrm{E})$ was also a good approximation. For this last mixture, each distribution could be associated with presence or absence of pathogens. The first 2 normal distributions appear to consist of uninfected cows and cows recovering from an infection, the third normal distribution may be associated with minor pathogens, and the fourth normal and the exponential distribution with major pathogens and persistent infections. Estimated percentages of records in each underlying distribution differed between parities, between stages of lactation, and between records with previous records being above or below 100,000 cells/ $\mathrm{mL}$. The categorical nature of cow-SCC can be utilized by deriving new traits such as the fraction of cow-SCC records in a lactation that are associated with an infection with a major pathogen.
\end{abstract}

Key words: somatic cell count, distribution, mastitis

\section{INTRODUCTION}

Somatic cell counts are often used as an indicator of mastitis. Animal breeders use SCC to quantify the cow's inherited sensitivity to clinical and subclinical

Received November 2, 2007.

Accepted September 23, 2008.

${ }^{1}$ Corresponding author: jan.tennapel@wur.nl mastitis (Shook, 1989). Farmers and veterinarians use SCC to detect subclinical intramammary infections (Schukken et al., 2003).

Because of the extremely skewed distribution of SCC, it is often transformed into SCS, which by the manner in which it is used, is presumed to be a continuous trait without a categorical nature (Detilleux and Leroy, 2000). In genetic programs, SCS is assumed to be genetically correlated linearly with clinical mastitis and other traits. This approach implicitly assumes that SCC of uninfected cows and of cows with an intramammary infection follow the same distribution.

An uninfected mammary gland has a low SCC, predominantly consisting of macrophages and lymphocytes. Following a microbial infection, the number of neutrophils in particular increases dramatically within hours, taking the SCC from fewer than $10^{5}$ cells $/ \mathrm{mL}$ of milk to well in excess of $10^{6}$ cells $/ \mathrm{mL}$ (Kehrli and Shuster, 1994). Following successful elimination of the infection, it may take $3 \mathrm{wk}$ for the SCC to return to preinfection levels (VanWerven et al., 1997).

In udder health research, several studies attempted to move away from the continuous trait approach of SCS (Detilleux and Leroy, 2000; Heringstad et al., 2003; Odegard et al., 2003). All of these studies a priori modeled "uninfected" and "infected" as 2 normal distributions of log-transformed SCC (i.e., SCS) with different means in a mixture model approach. This concept of a bivariate nature of SCC makes sense intuitively, but has never been tested. Other approaches focused on patterns of peak SCC (de Haas et al., 2004) or distribution characteristics (Green et al., 2004). The distinction between SCC of uninfected cows and SCC of infected cows may provide an opportunity to select against the probability of infection in the presence of pathogens. The distinction may also provide veterinary research with alternative measures of udder health and it may improve veterinary advice and health management, for example, by analytically deriving the thresholds for suspected subclinical mastitis.

Therefore, the overall objective of this paper is to study the statistical distribution of SCC values from a biological perspective. If there are 2 patterns of SCC, one resulting from uninfected and one from infected 
cows, then the distribution of SCC observations should be a mixture of at least 2 distributions.

The first objective is to find evidence for the presence of 2 or more patterns of SCC. We use SCC of individual quarters (designated quarter-SCC), along with the results of bacteriological culturing, for this purpose. Although not readily available in practice, bacteriology data should give a better understanding of the biology of SCC than SCC solely in samples of milk from 4 quarters with unknown health status (designated cow-SCC). The second objective is to explore how this distinction in the distributions of SCC in cows with a different mastitis infection status could be exploited in the utilization of cow-SCC in animal breeding and veterinary practice for achieving a sustainable reduction in clinical mastitis.

\section{MATERIALS AND METHODS}

\section{Quarter-SCC}

The SCC of individual quarters were determined as part of a service for bacteriological testing of samples of individual quarters (GD Animal Health Service, Deventer, the Netherlands). This testing service is available for cows with a high SCC in the milk production recording or may be requested by a farmer or a veterinarian for any other reason. Quarter milk samples were generally collected from the first milk after discarding the first few hand-stripped milk squirts, instead of collecting it from the total milk as would be the case for composite cow-SCC. Quarter-SCC was determined for the sample, unless the milk was visibly abnormal, as judged by the laboratory. Quarter-SCC was not routinely collected on cows and although $43 \%$ of the Dutch dairy cattle herds submitted at least one sample between 1999 and 2006, only $2 \%$ did so regularly. Quarter-SCC was determined using the Fossomatic (Foss, Hillerød, Denmark) in a single laboratory. The majority of the quarter-SCC samples were from cows with an elevated SCC in participating herds.

A total of 155,190 sets of one or more quarters from 133,102 cows in 11,152 herds resulted in 450,834 valid records of quarters with results of bacteriological culturing (data set A). Somatic cell counts could be determined for 415,112 records. The records were collected from September 1999 through April 2006. Among these sets were 80,804 complete sets $(323,216$ quarter records) with SCC and culturing results available for all 4 quarters. The complete sets were from 72,285 cows of unknown parity in 7,623 herds. Only $9 \%$ of the cows had more than one record included in the data. Data set A was divided into 3 subsets based on the results of bacteriological culturing. The first subset consisted of quarters with a negative culture
( $\mathrm{n}=258,270$ quarters). The second subset contained quarters that were positive only for minor pathogens ( $\mathrm{n}=99,557$ quarters) and the third subset were the quarters that were positive for a major pathogen (n $=93,007$ quarters). Following Schukken et al. (2003), we considered Streptococcus agalactiae, Staphylococcus aureus, environmental streptococci, Mycoplasma spp., Escherichia coli, Klebsiella spp., Serratia spp., and Arcanobacter pyogenes to be major pathogens. Any other pathogen was considered minor.

\section{Cow-SCC}

Somatic cell count collected as part of the milk production recording scheme (cow-SCC) was determined in composite samples drawn from the cow's milk yield in the 2 or 3 milkings sampled in a 24 -h period. The time between test days was more or less fixed for each farm but ranged from 3 to 6 wk. Cow-SCC was routinely collected for a large portion of the Dutch dairy cattle population.

Cow-SCC was determined in the same laboratory and using the same equipment as quarter-SCC. The log-transformation used in this study to calculate SCS from cow-SCC was SCS $=\log _{2}(\mathrm{SCC} / 100,000)+3($ Ali and Shook, 1980).

A total of 335,135 test-day records of cow-SCC were collected from 2 management information systems (data set B). All herds that gave permission to use their data and recorded clinical mastitis were included (407 herds with 41,567 cows). The number of lactations in this data set was 57,193 . Records with less than 1,000 cells/ $\mathrm{mL}$ or a missing value $(\mathrm{n}=18,600)$ or with more than $10^{7}$ cells $/ \mathrm{mL}(\mathrm{n}=109)$ were excluded from the data. High values were discarded because a large proportion of SCC exceeding $10^{7}$ cells $/ \mathrm{mL}$ was by default recorded as $9,999,000$ cells $/ \mathrm{mL}$.

A second independent set of cow-SCC data was used to verify the results of the data set B. A total of 1,665,431 test-day cow-SCC records were available from a total of 1,578 farms (data set C). The number of cows and lactations in the data was 58,070 and 172,572, respectively. The data included all test-day records in the lifetime of cows that were involved in an experiment of the Dutch Udder Health Center (UGCN, Deventer, the Netherlands) to record all clinical mastitis cases on 396 herds from July 1, 2004 through June 30, 2005. Records with less than 1,000 cells $/ \mathrm{mL}$ or a missing value $(\mathrm{n}=118,484)$ or with more than $10^{7}$ cells $/ \mathrm{mL}(\mathrm{n}=$ 377) were excluded from the data.

\section{Descriptive Analysis of Distributions}

Before attempting an analysis, the characteristics of the raw data were considered. The distributions of 
quarter-SCC were plotted for each subset based on the results of bacteriological culturing. Because parity and stage of lactation are known to influence cow-SCC (Schepers et al., 1997), data set B was divided by 1) parity into 4 subsets and 2) stage of lactation into 8 subsets, and data set $\mathrm{C}$ was divided by 3 ) the previous SCC record exceeding a threshold of 100,000 cells/mL into 2 subsets and 4 ) the previous 2 SCC records exceeding the threshold into 4 subsets. The distributions of subsets and the entire set were then plotted. The idea of using a threshold came from Schepers et al. (1997). The threshold of 100,000 cells/mL for cow-SCC was chosen visually from the graph of the entire set. The criterion was that the distribution on the left hand side of the threshold should be as symmetric as possible. We compared all these graphs visually for shape and location of the peak of the distribution. To characterize the distribution of observations, we also calculated raw means and standard deviations of SCC and SCS.

\section{Describing the Distribution of Cow-SCC by Approximations}

For each analysis, SCC were grouped in classes of 1,000 cells $/ \mathrm{mL}$ and the number of records in each class was counted. The distributions of cow-SCC and quarter-SCC are not standard distributions. We therefore tried to find a mixture of density functions that approximately described the distribution of cow-SCC. A range of mixed density functions, involving up to 5 normal, log-normal, or exponential density functions were fitted on the number of records per class of 1,000 cells/mL. Parameters of these density functions were estimated with a FORTRAN program MIXDIS (ten Napel et al., 1995; ten Napel and Johnson, 1997) using the algorithm of Agha and Ibrahim (1984) to estimate parameters of mixture distributions with a maximum likelihood approach.

Unlike a normal distribution, which is defined from minus infinity to infinity, an exponential distribution is defined from zero to infinity and hence has a starting point. In the original algorithm, the exponential distribution always begins with class zero. The algorithm was extended to evaluate a range of starting points with steps of 1,000 cells $/ \mathrm{mL}$. The starting point with the highest likelihood was considered to provide the best fit.

A second FORTRAN program, using functions from Press et al. (1989), was used to predict the number of observations per class from the total number of observations and the estimated parameters of the mixed density function. Residual variance was calculated as the variance of the deviations of the predicted num- ber from the observed number in each SCC class. The residual variance was presented as a proportion of the variance in the observed incidence of each SCC class. The fit of a reduced model compared with a full model was tested using a likelihood ratio test. The fit of the reduced model was considered better if the statistic was lower than the right hand value of an $\chi^{2}$ distribution with a number of degrees of freedom equal to the difference in number of parameters estimated between the reduced and the full models.

\section{Estimation of Parameters of Underlying Density Functions for Quarter-SCC}

The 2 types of mixed density function that were most appropriate for the distribution of cow-SCC were also fit on data sets of quarter-SCC. In addition to the entire data set $\mathrm{A}$, these mixed density functions were fit on subsets of records with a negative culture result, records with a positive result for minor pathogens only and records that were positive for a major pathogen.

\section{Applying the Approximate Mixture to Subsets of Data}

As parameters of approximate density functions were very similar between data sets $\mathrm{B}$ and $\mathrm{C}$ and peaks of distributions were in the same place in almost all sets and subsets of cow-SCC, we concluded that differences in means and standard deviations between subpopulations were largely caused by a shift of records from one distribution to another, rather than by a change of the distributions. We therefore analyzed subsets of data set $\mathrm{B}$ by 1) parity or 2) stage of lactation and subsets of data set C by 3) previous SCC exceeding 100,000 cells/ $\mathrm{mL}$ or 4) the previous 2 SCC exceeding 100,000 cells/ $\mathrm{mL}$, using the best fitting mixture of the entire set for a mixture of 4 normal distributions and an exponential distribution. We fixed the parameters of the underlying distributions at the values estimated for the entire data set $\mathrm{C}$, but the proportions of each underlying distribution were estimated using the MIXDIS software described above. The same procedure was used for subsets of quarter-SCC data, keeping the distribution parameters of the best fitting mixture for data set A fixed, but allowing the proportions to vary.

Differences in numbers of records per distribution between independent subsets were tested using the Pearson chi-squared test with number of degrees of freedom equal to the number of possible outcomes minus 1 . The number of possible outcomes is the number of independent subsets tested simultaneously times the number of distributions. 

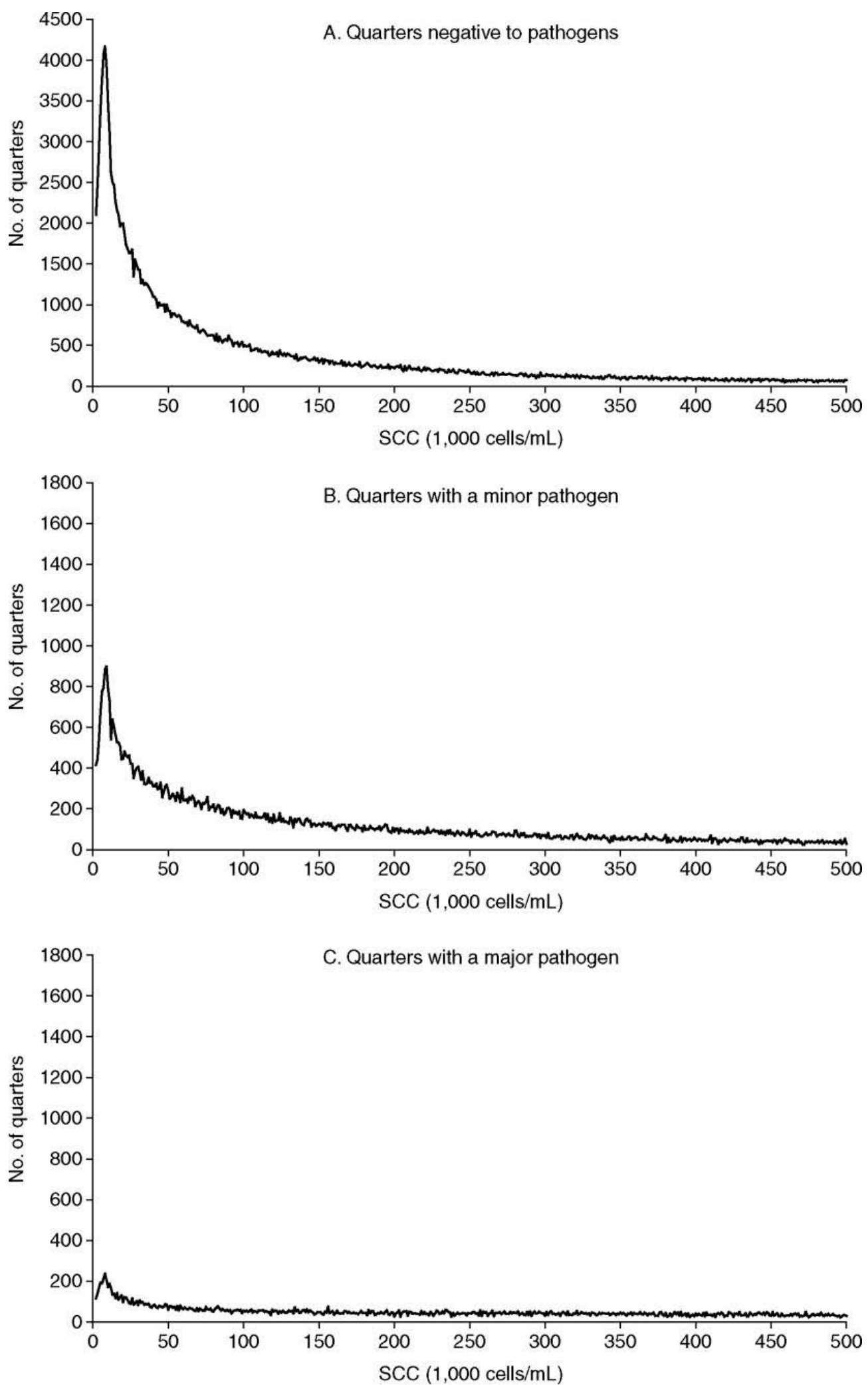

Figure 1. Distribution of quarter-SCC from $10^{3}$ to $5 \times 10^{5}$ cells $/ \mathrm{mL}$ (A) for quarters with a negative result from culturing $(\mathrm{n}=258,270$ quarters), (B) for quarters with a minor pathogen ( $\mathrm{n}=99,557$ quarters) and (C) for quarters with a major pathogen $(\mathrm{n}=93,007$ quarters). The scale of the y-axis is proportional to the total number of records in the subset. Streptococcus agalactiae, Staphylococcus aureus, environmental streptococci, Mycoplasma spp., Escherichia coli, Klebsiella spp., Serratia spp., and Arcanobacter pyogenes were considered to be major pathogens. 

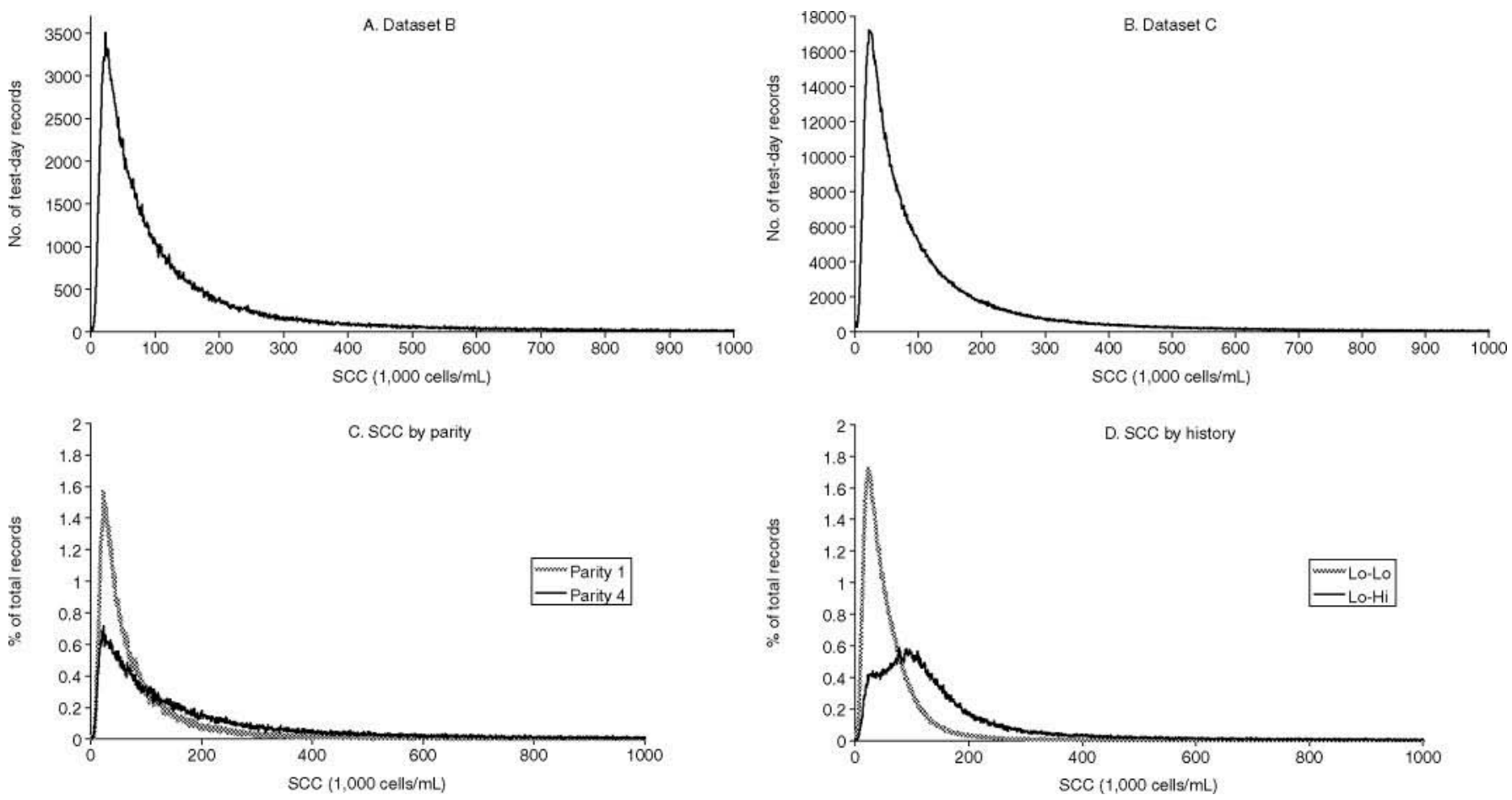

Figure 2. Distribution of cow-SCC observations between $10^{3}$ and $10^{6}$ cells $/ \mathrm{mL}$ in $(\mathrm{A})$ the entire data set $\mathrm{B}(\mathrm{n}=316,426$ records), (B) the entire data set $\mathrm{C}(\mathrm{n}=1,546,570$ records $),(\mathrm{C})$ for cows in data set $\mathrm{B}$ with parity $1(\mathrm{n}=96,105$ records $)$ or parity 4 or higher $(\mathrm{n}=85,069$ records $)$ and (D) for cows in data set $\mathrm{C}$ with the previous 2 test-day SCC below 100,000 cells/mL (Lo-Lo; $\mathrm{n}=787,917$ records) or the last record above and the record before last below 100,000 cells $/ \mathrm{mL}(\mathrm{Lo}-\mathrm{Hi} ; \mathrm{n}=168,393)$

\section{Characterization by Pathogen}

To study culture-positive samples with a low SCC in more detail, we identified the pathogens that were found in $5 \%$ or more of the quarters within the subsets of quarters positive for a minor pathogen and quarters positive for a major pathogen. We evaluated within subsets whether the proportion of records by pathogen was different between low-SCC quarters and all quarters, using the Pearson chi-squared test.

\section{RESULTS}

\section{Descriptive Analysis of Distributions of Cow-SCC and Quarter-SCC Observations}

The distributions of quarter-SCC in data set A (Figure 1) and cow-SCC in data set B and C (Figure 2A-B) were similar in shape. Typical for distributions of large numbers of SCC observations is the steep incline to a narrow peak, followed by an initially steep decline, but soon leveling off into a very long tail. The distribution of SCC in quarters with a negative culture result (Figure $1 \mathrm{~A}$ ) had the same peak as that of SCC in quarters with a positive result from either a minor or a major pathogen (Figure $1 \mathrm{~B}$ and $\mathrm{C}$, respectively). Infection appeared to cause a shift of records from the peak to the tail. This result was more pronounced for infections with a major pathogen.

For all quarter milk subsets, the peak of the distribution of quarter-SCC in foremilk samples was found at either 7,000 or 8,000 cells $/ \mathrm{mL}$ despite the differences in mean. Similarly, in most of the sets or subsets of cow-SCC analyzed, even with very different statistical means of SCC and SCS, the peak of the distribution was found between 22,000 and 24,000 cells/mL (Table 1). For subsets with a statistical mode higher than 25,000 cells/mL (Table 1 ), there was still a local peak visible between 22,000 and 24,000 cells/mL (see for example Lo-Hi in Figure 2D).

\section{Describing the Distribution of Cow-SCC}

The distributions of quarter-SCC and cow-SCC were not standard distributions. Estimates of parameters of mixed distributions that approximately described the distribution of cow-SCC were presented in Table 2. A mixture with 2 log-normal density functions $(\mathbf{2 L N})$, a mixture with a normal, a log-normal and an exponential density function $(\mathbf{N}+\mathbf{L N}+\mathbf{E})$ and a mixture with 4 normal and an exponential density function $(\mathbf{4 N}+\mathbf{E})$ had the lowest residual variation. Each of these 3 
Table 1. Statistical mode (peak) of SCC and mean and standard deviation of SCC and SCS in various subsets of data

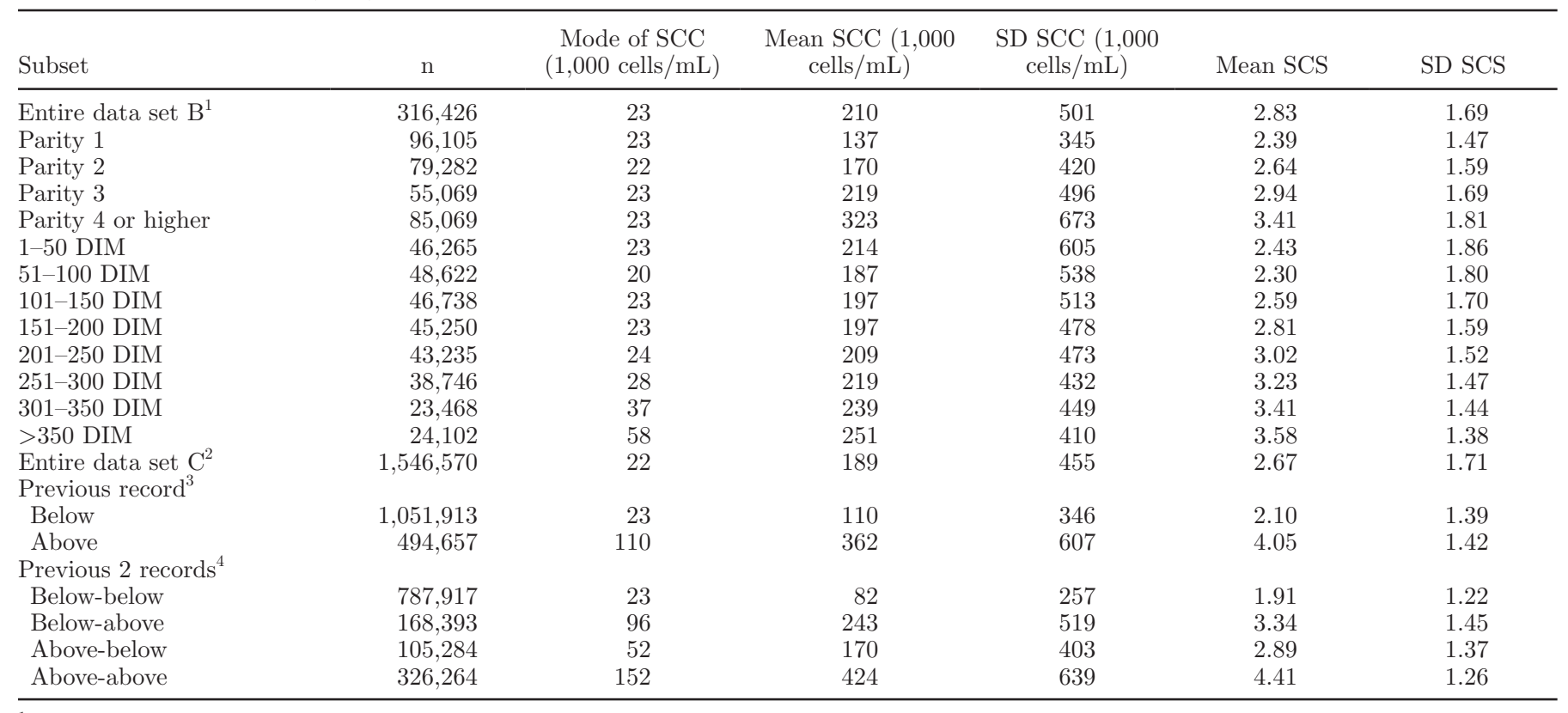

${ }^{1}$ Data set B consists of records of 41,567 cows on 407 farms.

${ }^{2}$ Data set $\mathrm{C}$ consists of records of 58,070 cows on 1,578 farms.

${ }^{3}$ Previous record $=$ SCC grouped by the previous test-day record being below or above the chosen threshold of 100,000 cells $/ \mathrm{mL}$.

${ }^{4}$ Previous 2 records $=$ SCC grouped by the previous 2 test-day records being below or above the chosen threshold of 100,000 cells $/ \mathrm{mL}$.

mixtures was superior to simpler mixtures with one or more of the density functions removed $(P<0.001)$. The mixtures $4 \mathrm{~N}+\mathrm{E}$ and $2 \mathrm{LN}$, and to a lesser extent the mixture $\mathrm{N}+\mathrm{LN}+\mathrm{E}$, still had areas with systematic overestimation or underestimation of the number of observations per SCC class (Figure 3). The parameters estimated for the independent data sets $\mathrm{B}$ and $\mathrm{C}$ were similar.

\section{Parameters of the Underlying Density Functions of Quarter-SCC}

The mixture $\mathrm{N}+\mathrm{LN}+\mathrm{E}$ yielded lower residual variances than the mixture $4 \mathrm{~N}+\mathrm{E}$, except for the subset positive for a major pathogen (Table 3). When fitting $4 \mathrm{~N}+\mathrm{E}$ on SCC of negative quarters, SCC of quarters positive for a minor pathogen only and SCC of quarters positive for a major pathogen, it appeared that the parameters of the first 3 underlying normal distributions were reasonably similar, but the parameters of the fourth normal and the exponential distribution increased when going from negative quarters and quarters positive for minor pathogens to quarters positive for major pathogens (Table 3). The proportion of records in the first 2 normal distributions decreased and the proportion of records in the exponential distribution increased, when going from negative quarters and quarters positive for minor pathogens to quarters positive for major pathogens. The parameters of the subsets were also similar to the parameters of the full set. For the mixture $\mathrm{N}+\mathrm{LN}+\mathrm{E}$, the estimated parameters were similar for negative quarters and quarters positive for a minor pathogen, but not for the subset positive for a major pathogen. For the latter subset, the mixture $\mathrm{N}+\mathrm{LN}+\mathrm{E}$ yielded a very flat and wide log-normal distribution and an exponential distribution containing the majority of the records ( $82 \%$, Table 3$)$.

\section{Applying the Approximate Mixture to Subsets of Data}

Proportions of underlying distributions varied greatly between subsets of data set B and C. Subsets with the previous SCC record being either below or above $10^{5}$ cells $/ \mathrm{mL}$ and the 2 previous SCC records being either below or above $10^{5}$ cells $/ \mathrm{mL}$ showed the largest contrast in proportions (Table 4). The proportion of the exponential distribution increased substantially with increasing parity, from 0.10 to $0.14,0.20$, and 0.33 for parity $1,2,3$, and $\geq 4$, respectively. For stage of lactation, it was the first normal distribution that substantially decreased and the third and fourth normal distributions that substantially increased with increasing days in milk.

When applying the most appropriate mixed density function for quarter-SCC to subsets of data set A, the number of records in the first normal distribution decreased and the number of records in the exponen- 
Table 2. Parameters of underlying distributions and residual variances of the prediction of the distribution of cow-SCC observations with mixtures of normal $(\mathrm{N})$, log-normal (LN), and exponential (E) distributions

\begin{tabular}{|c|c|c|c|c|c|c|c|c|c|c|}
\hline \multirow[b]{2}{*}{ Type } & \multicolumn{3}{|c|}{ Normal distribution $^{1}$} & \multicolumn{3}{|c|}{ Log-normal distribution ${ }^{2}$} & \multicolumn{3}{|c|}{ Exponential distribution $^{3}$} & \multirow[b]{2}{*}{$\% \mathrm{RV}^{4}$} \\
\hline & $\mathrm{p}_{\mathrm{N}}$ & $\operatorname{Mean}_{N}$ & $\mathrm{SD}_{\mathrm{N}}$ & $\mathrm{p}_{\mathrm{LN}}$ & Mean $_{\mathrm{LN}}$ & $\mathrm{SD}_{\mathrm{LN}}$ & $\mathrm{p}_{\mathrm{E}}$ & Mean $_{\mathrm{E}}$ & Start $_{\mathrm{E}}$ & \\
\hline LN & & & & 1.00 & 88.7 & 3.22 & & & & 4.6 \\
\hline \multirow[t]{2}{*}{$2 \mathrm{LN}$} & & & & 0.65 & 55.5 & 2.27 & & & & 1.5 \\
\hline & & & & 0.35 & 210 & 3.40 & & & & \\
\hline $\mathrm{N}+\mathrm{LN}$ & 0.12 & 31.0 & 10.1 & 0.88 & 103 & 3.18 & & & & 2.3 \\
\hline $\mathrm{N}+\mathrm{LN}+\mathrm{E}$ & 0.04 & 13.8 & 2.60 & 0.40 & 181 & 3.59 & 0.56 & 61.3 & 17 & 1.2 \\
\hline \multirow[t]{2}{*}{$2 \mathrm{~N}+\mathrm{E}$} & 0.35 & 35.5 & 15.8 & & & & 0.30 & 527 & 11 & 6.2 \\
\hline & 0.35 & 108 & 49.9 & & & & & & & \\
\hline \multirow[t]{3}{*}{$3 \mathrm{~N}+\mathrm{E}$} & 0.25 & 27.1 & 10.0 & & & & 0.23 & 534 & 39 & 2.4 \\
\hline & 0.30 & 65.5 & 24.9 & & & & & & & \\
\hline & 0.22 & 154 & 61.4 & & & & & & & \\
\hline $4 \mathrm{~N}+\mathrm{E}$ & 0.19 & 24.1 & 8.22 & & & & 0.19 & 625 & 33 & 1.3 \\
\hline $2 \mathrm{LN}$ & & & & 0.36 & 177 & 3.52 & & & & \\
\hline $\mathrm{N}+\mathrm{LN}+\mathrm{E}$ & 0.09 & 17.5 & 4.47 & 0.40 & 158 & 3.67 & 0.61 & 60.9 & 22 & 1.1 \\
\hline \multirow{4}{*}{$4 \mathrm{~N}+\mathrm{E}$} & 0.23 & 24.7 & 9.00 & & & & 0.13 & 813 & 35 & 1.4 \\
\hline & 0.27 & 54.4 & 19.4 & & & & & & & \\
\hline & 0.24 & 115 & 41.8 & & & & & & & \\
\hline & 0.13 & 247 & 96.8 & & & & & & & \\
\hline
\end{tabular}

${ }^{1} \mathrm{p}_{\mathrm{N}}$, mean $_{\mathrm{N}}$, and $\mathrm{SD}_{\mathrm{N}}=\%$ of records, mean, and standard deviation of normal distribution.

${ }^{2} \mathrm{p}_{\mathrm{LN}}$, mean $_{\mathrm{LN}}$, and $\mathrm{SD}_{\mathrm{LN}}=\%$ of records, mean and standard deviation of log-normal distribution (on the observed scale).

${ }^{3} \mathrm{p}_{\mathrm{E}}$, mean $_{\mathrm{E}}$, and $\operatorname{start}_{\mathrm{E}}=\%$ of records, mean and starting position of exponential distribution.

${ }^{4} \% \mathrm{RV}=$ residual variance as a percentage of total variance.

${ }^{5}$ Data set B consists of records of 41,567 cows on 407 farms.

${ }^{6}$ Data set $\mathrm{C}$ consists of records of 58,070 cows on 1,578 farms.

tial distribution increased when going from negative cultures or cultures with a minor pathogen to cultures with a major pathogen (Table 5). The negative quarters of cows with a major pathogen in at least one quarter had slightly more records in the third normal distribution and slightly fewer in the exponential distribution than negative quarters of cows with a minor infection or with negative cultures for all quarters. Quarters of culture-negative cows had more records in the exponential distribution than negative quarters of cows with one or more records positive for any pathogen.

\section{Characterization by Pathogen}

For all common pathogens, the proportion of quarters that were positive for that specific pathogen differed between the full subset and quarters in the subset with an SCC below 50,000 cells $/ \mathrm{mL}(P<0.01)$. This was true both for the subset of quarters with only a minor pathogen and the subset of quarters with a major pathogen (Table 6).

\section{DISCUSSION}

There is evidence in the distribution of SCC values that some SCC are an indication of a uninfected udder or quarter and others are indicative of a response to infection or a recovery from an infection. The distributions of cow-SCC and quarter-SCC are best described by a normal, a log-normal, and an exponential distribution. Approximately describing the observed distribution by a mixture of 4 normal and 1 exponential distribution provides an opportunity to distinguish uninfected cows from cows infected with minor or major pathogens.

\section{Distributional Characteristics of SCC}

The evidence presented in this study for the existence of multiple underlying distributions is compelling and consistent. The peak in the distributions of the various subsets of cow-SCC is independent of the mean, but occurred at the same level of SCC for the majority of subsets (Table 1). The location of the peak was the same for quarter-SCC in subsets of quarters with a negative 

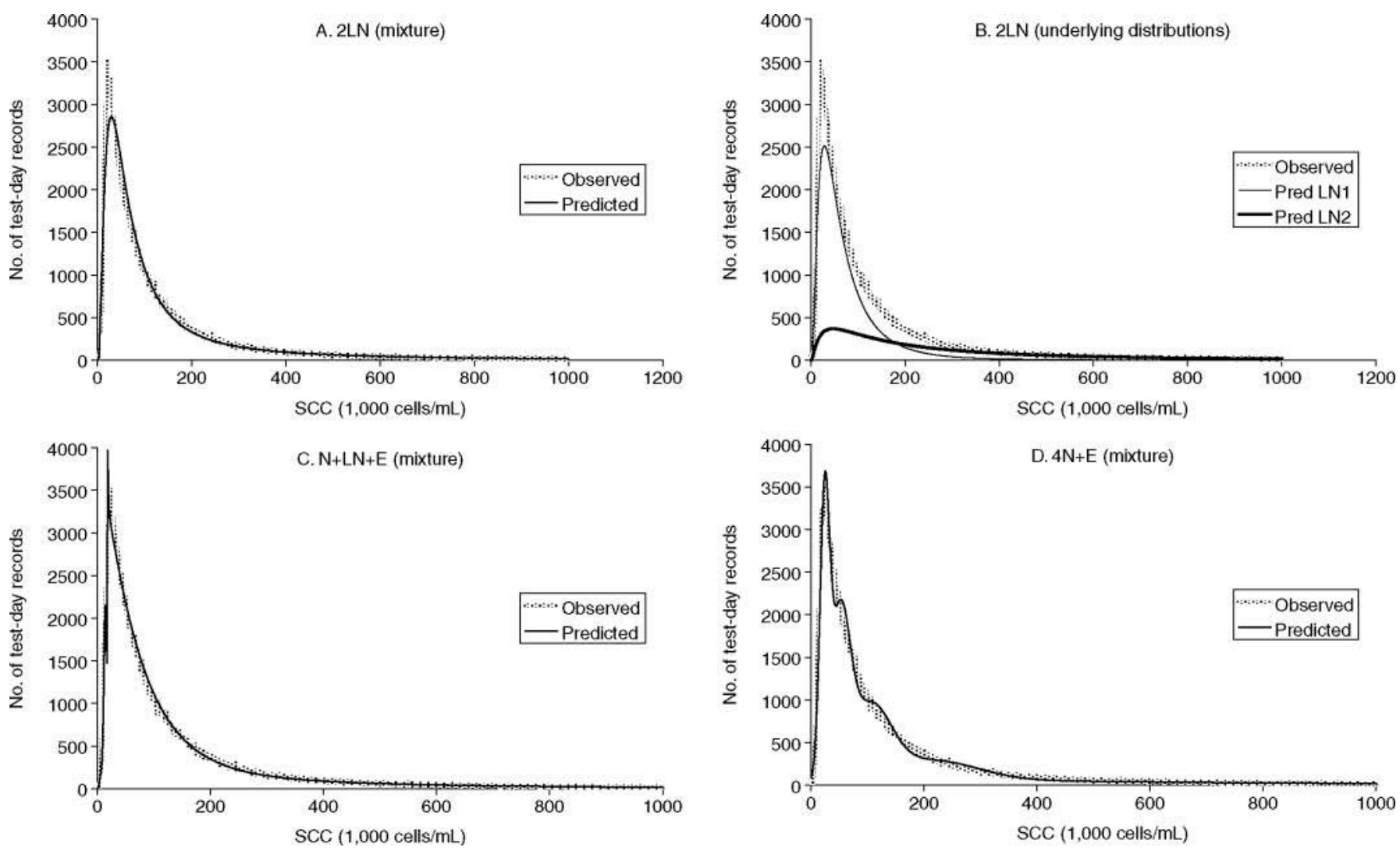

Figure 3. Observed (data set $\mathrm{B} ; \mathrm{n}=316,426$ records) and predicted number of cow-SCC from $10^{3}$ to $10^{6}$ cells $/ \mathrm{mL},(\mathrm{A}$ and $\mathrm{B})$ using a mixture of 2 log-normal density functions (2LN), (C) a normal, a log-normal and an exponential density function (N+LN+E) and (D) 4 normal and an exponential distribution $(4 \mathrm{~N}+\mathrm{E})$.

culture result, quarters positive for a minor pathogen, and quarters with a major pathogen (Figure 1). Fitting the combination of 4 normal and 1 exponential distribution on these subsets of quarter-SCC yielded similar parameters but a very different proportion of records in each underlying distribution (Table 3 ). Two very large independent sets of cow-SCC also yielded very similar parameters (Table 2).

Underlying distributions relate to the absence or presence of pathogens. The main difference between the distributions of culture-negative quarters and quarters positive for a major pathogen was the relative proportion of records in the peak and the tail of the distribution (Figure 1 and Table 3 ). This strongly suggests an association between the peak of the distribution and absence of infection and between the tail of the distribution and presence of an infection.

One way to categorize the health states of quarters is to distinguish 3 groups: 1) quarters that have not been infected for some time, 2) quarters that are experiencing a persistent or new infection, and 3) quarters that are recovering from a successful elimination of a pathogen. Quarter SCC of the first group is below 25,000 cells/mL with only minor variation. Cow SCC for this group is well below 100,000 cells/mL. The distribution is characterized by a narrow peak, slightly skewed to the right (like Lo-Lo in Figure 2D). The second group is characterized by SCC well above 100,000 cells/mL, with an enormous variation resulting in a nearly flat distribution (Figure 1B and C). Indeed, SCC rises 10fold or higher within hours following infection (Sears et al., 1990). This is the result of a large number of immune factors acting in a concerted manner with a multiplicative effect on SCC. A large number of independent multiplicative effects results in a log-normal distribution (Limpert et al., 2001). When an infection has been eliminated successfully (culture-negative), SCC returns via a sigmoid curve back to preinfection levels (VanWerven et al., 1997). This may be explained by the multiplicative effects disappearing one by one. Sampling from this sigmoid curve yields a log-normal distribution (Limpert et al., 2001). Figure 1A matches the pattern of a log-normal distribution.

Based on the above, one could hypothesize that the distribution of SCC consists of a normal distribution of uninfected cows, an exponential distribution of infected cows, and a log-normal distribution of cows recovering from infection. Indeed, the mixture $\mathrm{N}+\mathrm{LN}+\mathrm{E}$ was 
Table 3. Parameters and residual variances of the prediction of the distributions of quarter-SCC observations with mixtures of normal (N), log-normal (LN), and exponential (E) distributions

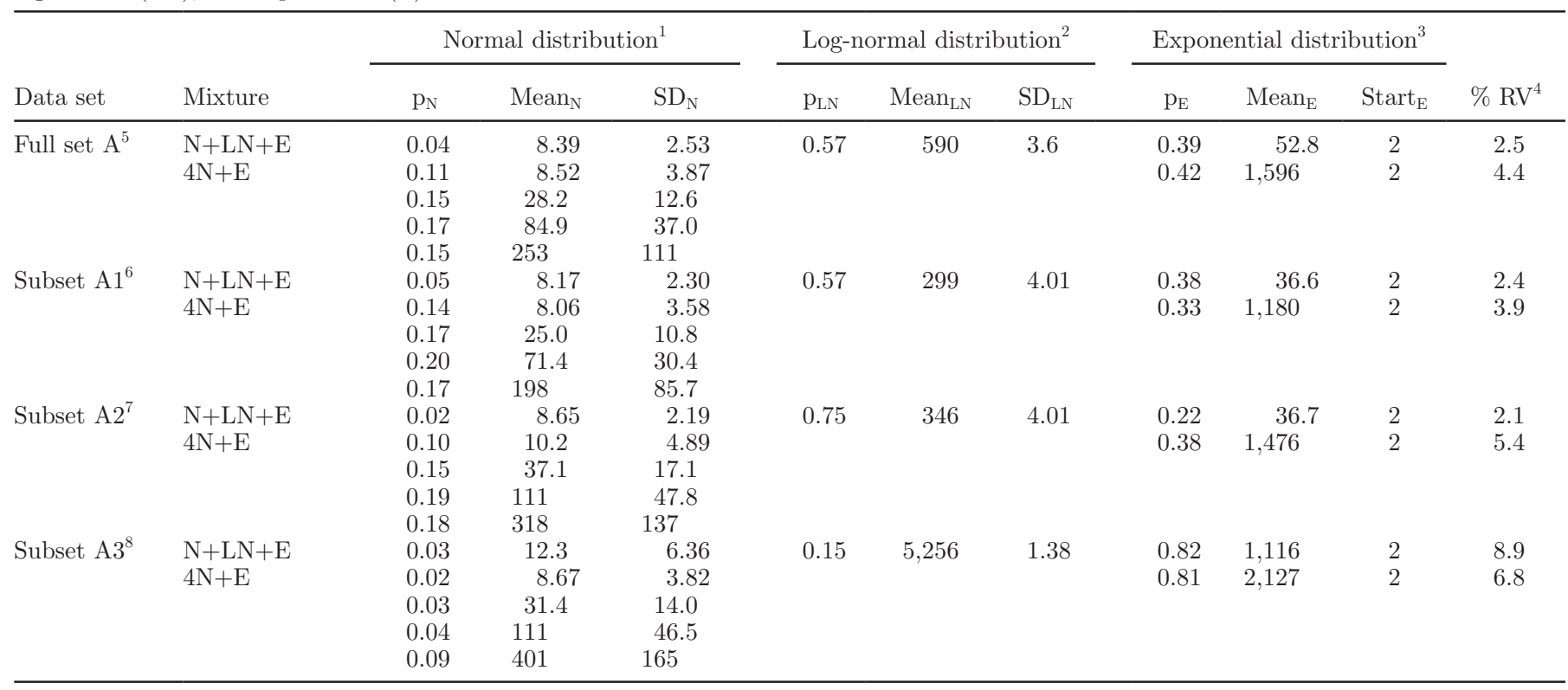

${ }^{1} \mathrm{p}_{\mathrm{N}}, \mathrm{Mean}_{\mathrm{N}}$, and $\mathrm{SD}_{\mathrm{N}}=\%$ of records, mean and standard deviation of normal distribution.

${ }^{2} \mathrm{p}_{\mathrm{LN}}, \mathrm{Mean}_{\mathrm{LN}}$, and $\mathrm{SD}_{\mathrm{LN}}=\%$ of records, mean and standard deviation of log-normal distribution (on the observed scale).

${ }^{3} \mathrm{p}_{\mathrm{E}}=\%$ of records in exponential distribution; mean $_{\mathrm{E}}$ and start $_{\mathrm{E}}=$ mean and starting position of exponential distribution.

${ }^{4} \% \mathrm{RV}=$ residual variance as a percentage of total variance.

${ }^{5}$ Data set A consists of records of 450,834 quarters.

${ }^{6}$ Subset A1 consists of quarters with a negative culture result ( $\mathrm{n}=258,270$ quarters).

${ }^{7}$ Subset A2 consists of quarters with a positive culture result only for a minor pathogen ( $\mathrm{n}=99,557$ quarters).

${ }^{8}$ Subset A3 consists of quarters with a positive culture result for a major pathogen ( $\mathrm{n}=93,007$ quarters).

Table 4. Proportions of underlying distributions of cow-SCC in subsets of data set $\mathrm{B}^{1}$ and $\mathrm{C}^{2}$, using the estimated density functions of the entire data set $\mathrm{C}$

\begin{tabular}{|c|c|c|c|c|c|c|c|}
\hline Subset class & Subset level & $\mathrm{n}$ & $\mathrm{p}_{\mathrm{N} 1}^{3}$ & $\mathrm{p}_{\mathrm{N} 2}{ }^{3}$ & $\mathrm{p}_{\mathrm{N} 3}{ }^{3}$ & $\mathrm{p}_{\mathrm{N} 4}{ }^{3}$ & $\mathrm{p}_{\mathrm{E}}^{3}$ \\
\hline$($ data set $\mathrm{C})$ & Above $^{4}$ & $1,168,679$ & 0.03 & 0.01 & 0.23 & 0.34 & 0.40 \\
\hline Previous 2 records $^{\mathrm{b}}$ & Below-below ${ }^{4}$ & 96,114 & 0.35 & 0.38 & 0.20 & 0.03 & 0.04 \\
\hline & Above-below $^{4}$ & 55,994 & 0.09 & 0.20 & 0.40 & 0.15 & 0.15 \\
\hline & Above-above $^{4}$ & 85,129 & 0.00 & 0.00 & 0.09 & 0.43 & 0.48 \\
\hline Parity $^{\mathrm{c}}$ & 1 & 96,105 & 0.26 & 0.32 & 0.23 & 0.10 & 0.10 \\
\hline \multirow{6}{*}{$\begin{array}{l}\text { Lactation stage }^{\mathrm{d}} \\
(\text { data set } \mathrm{B})\end{array}$} & $0-50 \mathrm{~d}$ & 46,265 & 0.35 & 0.25 & 0.14 & 0.07 & 0.19 \\
\hline & $51-100 \mathrm{~d}$ & 48,622 & 0.37 & 0.26 & 0.14 & 0.06 & 0.16 \\
\hline & $101-150 \mathrm{~d}$ & 46,738 & 0.25 & 0.29 & 0.21 & 0.08 & 0.18 \\
\hline & $151-200 \mathrm{~d}$ & 45,250 & 0.16 & 0.29 & 0.26 & 0.12 & 0.17 \\
\hline & $201-250 \mathrm{~d}$ & 43,235 & 0.11 & 0.26 & 0.29 & 0.17 & 0.18 \\
\hline & $251-300 \mathrm{~d}$ & 38,746 & 0.07 & 0.21 & 0.31 & 0.22 & 0.20 \\
\hline
\end{tabular}

${ }^{\mathrm{a}-\mathrm{d}}$ Subsets with a letter in common were tested for independence and all pairs are different $(P<0.01)$.

${ }^{1}$ Data set B consists of records of 41,567 cows on 407 farms.

${ }^{2}$ Data set $\mathrm{C}$ consists of records of 58,070 cows on 1,578 farms.

${ }^{3} \mathrm{p}_{\mathrm{Ni}}=$ proportion of records in ith normal distribution; $\mathrm{p}_{\mathrm{E}}=$ proportion of records in exponential distribution.

${ }^{4}$ Previous record $=$ SCC grouped by the previous test-day record being below or above the chosen threshold of 100,000 cells $/ \mathrm{mL}$. Previous 2 records $=$ SCC grouped by the previous 2 test-day records being below or above the chosen threshold of 100,000 cells $/ \mathrm{mL}$. 
Table 5. Proportions of underlying distributions of quarter-SCC in subsets of data set $\mathrm{A}^{1}$, using the estimated mixture density function of the entire data set

\begin{tabular}{|c|c|c|c|c|c|c|c|}
\hline Culture result for cow & Culture result quarter & Quarters, n & $\mathrm{p}_{\mathrm{N} 1}^{2}$ & $\mathrm{p}_{\mathrm{N} 2}^{2}$ & $\mathrm{p}_{\mathrm{N} 3}^{2}$ & $\mathrm{p}_{\mathrm{N} 4}{ }^{2}$ & $\mathrm{p}_{\mathrm{E}}{ }^{3}$ \\
\hline \multirow{2}{*}{ Any } & Minor pathogen ${ }^{\mathrm{a}}$ & 99,557 & 0.08 & 0.13 & 0.18 & 0.21 & 0.40 \\
\hline & Major pathogen ${ }^{\mathrm{a}}$ & 93,007 & 0.02 & 0.02 & 0.02 & 0.03 & 0.91 \\
\hline Major & Minor pathogen ${ }^{c}$ & 28,892 & 0.09 & 0.15 & 0.23 & 0.23 & 0.30 \\
\hline \multirow[t]{2}{*}{ Minor } & Negative $^{\mathrm{b}}$ & 60,901 & 0.18 & 0.20 & 0.21 & 0.17 & 0.24 \\
\hline & Minor pathogen ${ }^{\mathrm{c}}$ & 53,667 & 0.09 & 0.13 & 0.18 & 0.23 & 0.37 \\
\hline 3 quarters positive & Negative $^{\mathrm{d}}$ & 13,777 & 0.14 & 0.20 & 0.23 & 0.19 & 0.24 \\
\hline
\end{tabular}

${ }^{\mathrm{a}-\mathrm{d}}$ Subsets with a letter in common were tested for independence and all pairs are different $(P<0.01)$.

${ }^{1}$ Data set A consists of records of 133,102 cows on 11,152 farms.

${ }^{2} \mathrm{p}_{\mathrm{Ni}}=$ proportion of records in ith normal distribution.

${ }^{3} \mathrm{p}_{\mathrm{E}}=$ proportion of records in exponential distribution.

the best fitting mixed function (Tables 2 and 3 ), but the estimated underlying density functions cannot be interpreted as healthy, recovering, and infected cows. The log-normal distribution covers the full range of observations and hence includes healthy cows as well as recovering and infected cows. The normal and the exponential distributions merely cover the surplus of records in the peak and the tail.

The observation that $45 \%$ of culture-negative quarters was found in the tail of the distribution is largely explained by cows recovering from an infection (Schukken et al., 2003), but intermittent shedding of Staphylococcus aureus (Sears et al., 1990), as well as any other cause of a negative culture result of a sample containing pathogens (no-growths), may play a role too.

Of the culture-positive records, $21 \%$ of the samples positive for a minor pathogen and $4 \%$ of the samples positive for a major pathogen had an SCC in the first 2 normal distributions. This may be explained by contamination during the sampling process, the presence of bacteria populations in just the teat canal, or sampling between infection and the SCC surge, although the lat- ter will be rare, as the time between infection and the SCC surge is a matter of hours.

Figure 1, Table 3, and Table 5 also provide evidence that minor pathogens and major pathogens result in different distributions of SCC. Minor pathogens appear to be more associated with the third, and to some extent the fourth, normal distribution (Table 5). Major pathogens are more associated with the fourth normal and the exponential distribution (Tables 4 and $5)$. This is consistent with the results in Schukken et al. (2003). An explanation may be that minor infections are eliminated in a matter of days, but SCC takes up to $3 \mathrm{wk}$ to return to normal. It means that minor infections are only in about $10 \%$ of the cases (about $2 \mathrm{~d}$ out of $20 \mathrm{~d}$ ) sampled in the infected state and in $90 \%$ of the cases in the recovery state, whereas persistent infections with major pathogens are much more likely to be sampled in the infected state. Table 6 suggests that the distribution of SCC may even be dependent on specific pathogens, as the relative importance of pathogens was different for low-SCC quarters and all quarters.

Table 6. Proportions of total quarters and quarters with an SCC below 50,000 cells $/ \mathrm{ml}$ with a positive culture result for specific pathogens

\begin{tabular}{|c|c|c|c|c|}
\hline Subset & Pathogen & Total records, $\%$ & $\begin{array}{l}\text { Records with SCC } \\
<50,000 \text { cells } / \mathrm{mL}, \%\end{array}$ & $\operatorname{Prob}^{1}$ \\
\hline Minor & $\begin{array}{l}\text { CNS } \\
\text { Corynebacterium spp. } \\
\text { Bacillus spp. }\end{array}$ & $\begin{array}{c}\mathrm{n}=96,003 \\
53.8 \\
10.8 \\
6.9\end{array}$ & $\begin{aligned} \mathrm{n}= & 24,078 \\
& 49.4 \\
& 10.1 \\
& 11.9\end{aligned}$ & $\begin{array}{l}P<0.01 \\
P<0.05 \\
P<0.01\end{array}$ \\
\hline Major & $\begin{array}{l}\text { Staphylococcus aureus (penicillin sensitive) } \\
\text { Streptococcus uberis } \\
\text { Streptococcus dysgalactiae } \\
\text { Staphylococcus aureus (penicillin resistant) } \\
\text { Other streptococci }\end{array}$ & $\begin{aligned} \mathrm{n}= & 115,632 \\
& 18.5 \\
& 11.0 \\
& 7.7 \\
& 7.6 \\
& 4.9\end{aligned}$ & $\begin{array}{c}\mathrm{n}=9,431 \\
13.6 \\
6.4 \\
5.5 \\
10.1 \\
17.9\end{array}$ & $\begin{array}{l}P<0.01 \\
P<0.01 \\
P<0.01 \\
P<0.01 \\
P<0.01\end{array}$ \\
\hline
\end{tabular}

${ }^{1}$ Probability that pathogen and SCC being below or above 50,000 cells $/ \mathrm{mL}$ are independent. 
Table 7. Extract from look-up table to translate cow-SCC to the probability of no infection and the probability of a persistent infection by a major pathogen

\begin{tabular}{lcc}
\hline SCC $(1,000$ cells $/ \mathrm{mL})$ & $\begin{array}{c}\text { Probability of } \\
\text { no infection }\end{array}$ & $\begin{array}{c}\text { Probability of a } \\
\text { persistent infection by } \\
\text { a major pathogen }\end{array}$ \\
\hline 10 & 1.00 & 0 \\
20 & 0.98 & 0 \\
50 & 0.76 & 0 \\
100 & 0 & 0.15 \\
200 & 0 & 0.36 \\
500 & 0 & 1.00 \\
1,000 & 0 & 1.00 \\
\hline
\end{tabular}

The cause of the 3 -fold difference in peak SCC between cow-SCC and quarter-SCC is unclear. The use of foremilk samples for quarter-SCC samples may have played a role. Figure 1 in Olde Riekerink et al. (2007) suggests that for quarters without an infection, SCC increases during the milking. Sarikaya and Bruckmaier (2006), however, found no changes in SCC during the course of milking for cows with an average SCC below 100,000 cells $/ \mathrm{mL}$.

\section{Utilizing the Biological Aspects in Cow-SCC}

The log-normal distribution covering the full range of SCC observations makes the use of the mixture $\mathrm{N}+\mathrm{LN}+\mathrm{E}$ for characterization of populations difficult to interpret. A contribution of, for example, $10 \%$ from the normal distribution, $50 \%$ from the log-normal distribution, and $40 \%$ from the exponential distribution does not explain what percentage of records is from the peak of the distribution. The approximate mixture $4 \mathrm{~N}+\mathrm{E}$ is more suitable for characterizing populations, as the 4 normal distributions each only cover a small part of the range of SCC observations and overlap only locally. The fit of $4 \mathrm{~N}+\mathrm{E}$ was similar to $\mathrm{N}+\mathrm{LN}+\mathrm{E}$, but contains 2 more density functions. Although more normal distributions would have reduced the residual variation even further, we deemed that it would add more to the complexity of the model than to the prediction of numbers of observations per SCC class.

Observations in the fourth normal and the exponential distribution are associated with major pathogens (Table 5) and persisting infections: the proportion of these 2 distributions is particularly high after 2 previous SCC above 100,000 cells/mL (Table 4). Also, the parity effect on cow-SCC is largely caused by a shift of records to these 2 distributions. A possible explanation is that the number of animals infected with pathogens causing persisting infections increases with time and that these infections rarely disappear completely. There is no definitive answer in this study, as no parity information was available for quarter-SCC data. In contrast, the effect of stage of lactation is mainly caused by a shift from the first and second normal to the third normal distribution and to a lesser extent to the fourth normal and the exponential distribution.

No support was found for a relationship between milk yield per day and SCC, even though no milk production data were available for this study. If there were an effect of dilution for high milk yields, then the peak of SCC of uninfected cows would have been much wider. The narrow peak suggests that SCC of uninfected cows is regulated by the number of somatic cells per milliliter, rather than the total number of cells.

\section{Opportunities for Application}

The underlying distributions of cow-SCC can be utilized by transforming cow-SCC values to the probability of being a response to infection and to the probability of the response being to a persistent infection. These probabilities can be calculated or obtained from a look-up table (Table 7) and are used in addition to, or instead of, SCC as udder health indicators. These probabilities are somewhat dependent on the proportions of the underlying distributions that apply to the history, parity, and stage of lactation of the animal (Table 4), but in practice, these differences are small.

The use of these probabilities as udder health traits offers new opportunities for genetic improvement because selection for "the probability of no infection" may reduce the genetic sensitivity to infection in general and selection against "the probability of a persistent infection" may improve resistance to major pathogens. de Haas et al. (2008) used similar trait definitions, but with a threshold that is commonly used in practice $(150,000$ cells $/ \mathrm{mL})$, and found these traits to be heritable $\left(\mathrm{h}^{2}=0.03-0.08\right)$ and informative for clinical and subclinical mastitis in addition to lactation averages of SCC.

In light of the categorical nature of SCC, the common practice of genetic selection on log-transformed SCC, SCS, is more statistically convenient than biologically meaningful. The mixed normal mixture model approach (Heringstad et al., 2003; Odegard et al., 2003) a priori modeling uninfected and infected as 2 normal distributions of SCS with different means is better than the continuous approach (Detilleux and Leroy, 2000), but still a substantial number of high SCC observations end up in the first log-normal distribution, interpreted as uninfected. Also, a substantial part of the peak is covered by the second log-normal distribution, interpreted as infected (Figure 3B). Transforming SCC into one or more binary traits may put the emphasis where 
it is required: eliminating a problem rather than making it less serious. Whether the continuous, the mixture model, or the categorical approach is most effective in reducing clinical and subclinical mastitis and whether they are complementary still needs to be established.

Our approach also provides new opportunities for udder health management. With the mixtures presented in Table 2, it is possible to estimate lower thresholds for cows suspected to be infected and for persistent infections. If one sets a threshold at the SCC class where the third normal distribution starts to contribute the majority of the predicted number of observations, then the first threshold is at 75,000 cells $/ \mathrm{mL}$. Similarly, if one sets the threshold at the SCC class where the fourth normal distribution begins to contribute the majority of the predicted number of observations in the class, then the second threshold is at 161,000 cells $/ \mathrm{mL}$. The current threshold to detect animals with udder health problems in the Netherlands is 150,000 for heifers and 250,000 cells/mL for multiparous cows. The results of this study do not support the practice of using different thresholds for different parities. It appears that the current threshold particularly highlights persistent infections. The effect of parity on SCC appears to be caused by an increase in persistent infections, whereas the peak of apparently uninfected cows remains at the same level, regardless of parity.

A novel tool for veterinary advice could be to estimate the percentage of records in each distribution for SCC of a herd collected during the course of a year, similar to the percentages presented in Tables 4 and 5. This may give insight into the types of pathogens present in the herd.

\section{CONCLUSIONS}

Quarter-SCC has a similar distribution to cow-SCC, but peaks at an SCC that is 3 times lower than cow-SCC. Cow-SCC is best described by a mixture of a normal, a log-normal, and an exponential distribution. A mixture of 4 normal and one exponential distributions is a good approximation that is more suitable for practical use. The first 2 normal distributions can be interpreted to represent uninfected animals, the third normal distribution to reflect infections with minor pathogens, and the fourth normal and the exponential distribution to indicate animals with a persistent infection or an infection with a major pathogen. Uninfected animals have the same SCC distribution regardless of their age or stage of lactation. There is more information in SCC that can be utilized for reducing clinical and subclinical mastitis than is currently utilized in animal breeding and in veterinary research and practice.

\section{ACKNOWLEDGMENT}

This study is part of the 5-year mastitis program of the Dutch Udder Health Center and was financially supported by the Dutch Dairy Board.

\section{REFERENCES}

Agha, M., and M. T. Ibrahim. 1984. Maximum-likelihood estimation of mixtures of distributions. J. R. Stat. Soc. C. 33:327-332.

Ali, A. K. A., and G. E. Shook. 1980. An optimum transformation for somatic-cell concentration in milk. J. Dairy Sci. 63:487-490.

de Haas, Y., W. Ouweltjes, J. ten Napel, J. J. Windig, and G. de Jong. 2008. Alternative somatic cell count traits as mastitis indicators for genetic selection. J. Dairy Sci. 91:2501-2511.

de Haas, Y., R. F. Veerkamp, H. W. Barkema, Y. T. Grohn, and Y. H. Schukken. 2004. Associations between pathogen-specific cases of clinical mastitis and somatic cell count patterns. J. Dairy Sci. $87: 95-105$

Detilleux, J., and P. L. Leroy. 2000. Application of a mixed normal mixture model for the estimation of mastitis-related parameters. J. Dairy Sci. 83:2341-2349.

Green, M. J., L. E. Green, Y. H. Schukken, A. J. Bradley, E. J. Peeler, H. W. Barkema, Y. de Haas, V. J. Collis, and G. F. Medley. 2004. Somatic cell count distributions during lactation predict clinical mastitis. J. Dairy Sci. 87:1256-1264.

Heringstad, B., R. Rekaya, D. Gianola, G. Klemetsdal, and K. A Weigel. 2003. Genetic change for clinical mastitis in Norwegian cattle: A threshold model analysis. J. Dairy Sci. 86:369-375.

Kehrli, M. E. Jr., and D. E. Shuster. 1994. Factors affecting milk somatic cells and their role in health of the bovine mammary gland. J. Dairy Sci. 77:619-627.

Limpert, E., W. A. Stahel, and M. Abbt. 2001. Log-normal distributions across the sciences: Keys and clues. Bioscience 51:341-352.

Odegard, J., J. Jensen, P. Madsen, D. Gianola, G. Klemetsdal, and B. Heringstad. 2003. Detection of mastitis in dairy cattle by use of mixture models for repeated somatic cell scores: A Bayesian approach via Gibbs sampling. J. Dairy Sci. 86:3694-3703.

Olde Riekerink, R. G. M., H. W. Barkema, W. Veenstra, F. E. Berg, H. Stryhn, and R. N. Zadoks. 2007. Somatic cell count during and between milkings. J. Dairy Sci. 90:3733-3741.

Press, W. H., B. P. Flannery, S. A. Teukolsky, and W. T. Vetterling. 1989. Numerical Recipes (FORTRAN Version). Press Syndicate of the University of Cambridge, Cambridge, UK.

Sarikaya, H., and R. M. Bruckmaier. 2006. Importance of the sampled milk fraction for the prediction of total quarter somatic cell count. J. Dairy Sci. 89:4246-4250.

Schepers, A. J., T. J. G. M. Lam, Y. H. Schukken, J. B. M. Wilmink, and W. J. A. Hanekamp. 1997. Estimation of variance components for somatic cell counts to determine thresholds for uninfected quarters. J. Dairy Sci. 80:1833-1840.

Schukken, Y. H., D. J. Wilson, F. Welcome, L. Garrison-Tikofsky, and R. N. Gonzalez. 2003. Monitoring udder health and milk quality using somatic cell counts. Vet. Res. 34:579-596.

Sears, P. M., B. S. Smith, P. B. English, P. S. Herer, and R. N. Gonzalez. 1990. Shedding pattern of Staphylococcus aureus from bovine intramammary infections. J. Dairy Sci. 73:2785-2789.

Shook, G. E. 1989. Selection for disease resistance. J. Dairy Sci. 72:1349-1362.

ten Napel, J., A. G. De Vries, G. A. J. Buiting, P. Luiting, J. W. M. Merks, and E. W. Brascamp. 1995. Genetics of the interval from weaning to estrus in first-litter sows-Distribution of data, direct response of selection, heritability. J. Anim. Sci. 73:2193-2203.

ten Napel, J., and R. Johnson. 1997. Genetic relationships among production traits and rebreeding performance. J. Anim. Sci. 75:51-60.

Van Werven, T., E. N. Noordhuizen-Stassen, A. Daemen, Y. H. Schukken, A. Brand, and C. Burvenich. 1997. Pre-infection in vitro chemotaxis, phagocytosis, oxidative burst, and expression of $\mathrm{CD} 11 / \mathrm{CD} 18$ receptors and their predictive capacity on the outcome of mastitis induced in dairy cows with Escherichia coli. J. Dairy Sci. 80:67-74. 